\title{
ATMOSPHERIC NO2 PROFILES MEASURED WITH LIDAR DURING THE CINDI-2 CAMPAIGN
}

\author{
A.J.C. Berkhout ${ }^{1 *}$, L.F.L. Gast ${ }^{1}$, G.R. van der Hoff ${ }^{1}$, D.P.J. Swart ${ }^{1}$, M. Hoed ${ }^{2}$, M. Allaart ${ }^{2}$ \\ ${ }^{I}$ National Institute for Public Health and the Environment (RIVM), the Netherlands, \\ *stijn.berkhout@rivm.nl \\ ${ }^{2}$ Royal Netherlands Meteorological Institute (KNMI), the Netherlands
}

\begin{abstract}
From 12 to 28 September 2016, the CINDI-2 $\mathrm{NO}_{2}$ intercomparison campaign took place at the Cabauw research site in the Netherlands. Aimed principally at MAX-DOAS instruments, other techniques participated as well. The RIVM mobile lidar measured atmospheric $\mathrm{NO}_{2}$ profiles on six campaign days. Results show the development of $\mathrm{NO}_{2}$ concentrations during the day, as well as layered structures in the profiles. These were compared with profiles from other instruments.
\end{abstract}

\section{INTRODUCTION}

Measurements of atmospheric trace gases from satellites offer global coverage but need validation from ground-based data. The CINDI-2 campaign was set up to intercompare a suite of MAX-DOAS instruments. These instruments are to provide data for the validation of the upcoming Sentinel 5 and TROPOMI satellite missions, as profile information is highly relevant in satellite retrieval algorithms. In addition to slant column density measurements of $\mathrm{NO}_{2}, \mathrm{HCHO}, \mathrm{O}_{3}$, and $\mathrm{O}_{4}$, profile measurements and intercomparisons were included in the campaign objectives as well. CINDI-2, short for Cabauw Intercomparison of Nitrogen Dioxide Measuring Instruments 2, was the successor to the successful CINDI campaign held in 2009 [1]. An overview paper of this campaign is presented at this Conference by Arnoud Apituley.

\section{METHODOLOGY}

\subsection{The CINDI-2 campaign}

The campaign took place at the Cabauw Experimental Site for Atmospheric Research (CESAR), $51.971^{\circ} \mathrm{N}, 4.927^{\circ} \mathrm{E}, 0.7 \mathrm{~m}$ below mean sea level (Figure 1). A $213 \mathrm{~m}$ high meteo mast and a suite of meteorological, atmospheric and air quality instruments are always operational on the site. There are no sources of air pollution in the immediate vicinity. Depending on the wind direction, air at the site comes from the sea, or from densely populated and heavily industrialised areas, leading to a variety of conditions.

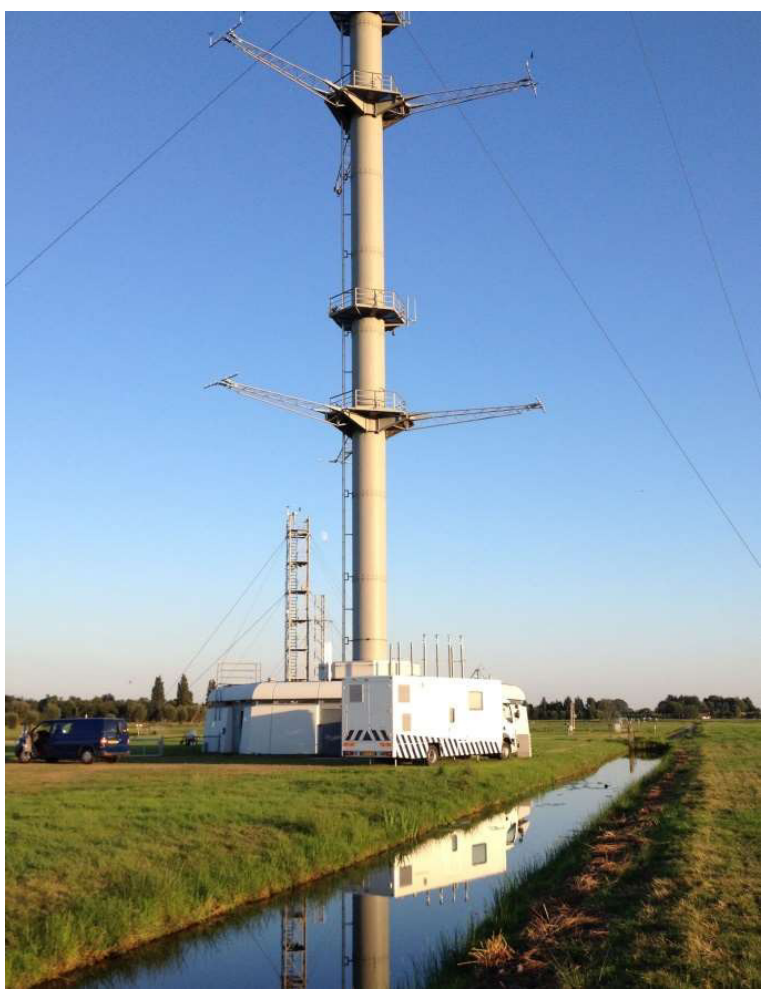

Figure 1. The Lidar vehicle at the site in Cabauw, next to the meteo mast.

Participants included 35 MAX-DOAS instruments from institutes from all over the world. Other measurement techniques, such as in-situ instruments and Lidars, participated as well. A profiling task team was set up, which aims to retrieve profile information from MAX-DOAS measurements and perform intercomparisons between these and other techniques. 


\subsection{The $\mathrm{NO}_{2}$ Lidar}

For this measurement campaign, the RIVM mobile Lidar system was used. This system is extensively described in [2], [3] and [4]. It measures either $\mathrm{NO}_{2}, \mathrm{SO}_{2}$ [3], $\mathrm{NH}_{3}$ [4] and benzene [5]. It uses the DIAL technique to measure concentration profiles of $\mathrm{NO}_{2}$ in the atmosphere.

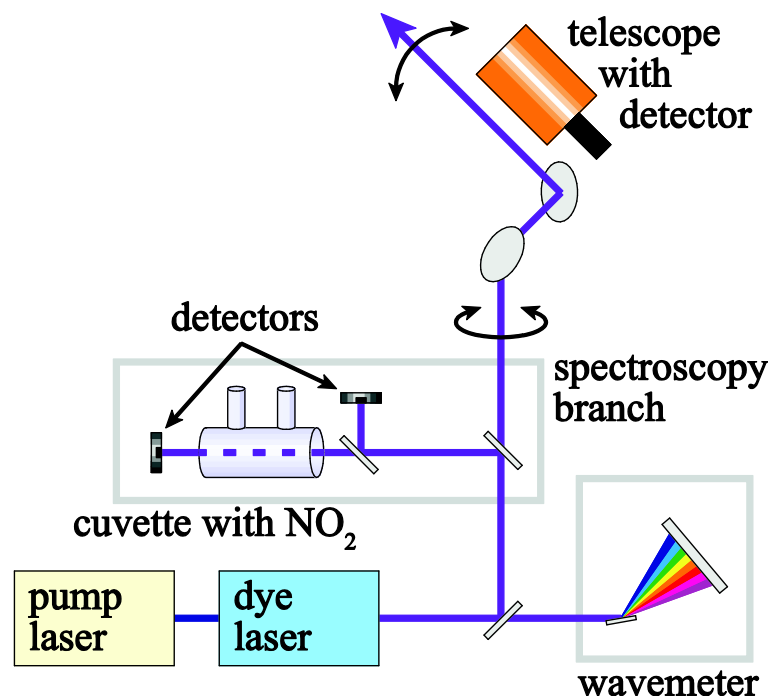

Figure 2. Schematic representation of the mobile Lidar DIAL system.

The lidar instrument (Figure 2) uses a SpectraPhysics Quanta-Ray Pro 250 pulsed Nd:YAG laser pumping a Sirah PrecisionScan PRSC-D-30 dye laser. The Exalite 411 dye used in this laser produces alternating wavelength pairs of $413.5382 \mathrm{~nm}$ (on) and $413.3775 \mathrm{~nm}$ (off), both wavelengths in vacuum. A wavemeter checks the wavelength of each pulse, if it has drifted too much, the dye laser is retuned. Output power of the dye laser is $30 \mathrm{~mJ}$ pulse ${ }^{1}$ at $30 \mathrm{~Hz}$. The spectroscopy branch shown in Figure 2 is used to determine the effective molecular cross section of the gas being measured. The instrument is housed in a fully self-supporting measurement vehicle.

\subsection{Lidar measurements of $\mathrm{NO}_{2}$ profiles}

When measuring $\mathrm{NO}_{2}$, the measurement range of the lidar runs from $300 \mathrm{~m}$ to about $2.5 \mathrm{~km}$. At ambient concentration levels, typically only one or two concentration values are derived over this interval. To arrive at a higher vertical resolution, measurements at eight different elevation angles are combined (see Figure 3).

Profiles were obtained consisting of about six or seven values inside the planetary boundary layer, and, depending on atmospheric conditions, one above this layer. The vertical resolution of a profile varies (see the vertical bars illustrating this in Figure 3). It ranges from $7.5 \mathrm{~m}$ in the lowest part of the profile to $800 \mathrm{~m}$ above the boundary layer.

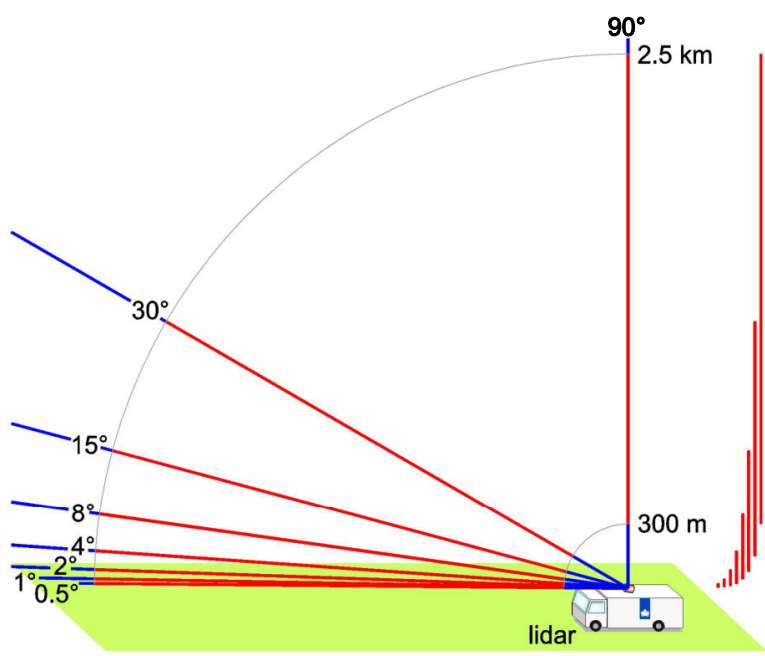

Figure 3. Construction of a vertical NO2 concentration profile from a set of measurements at different elevations. The vertical bars on the right illustrate the altitude intervals to which the measured NO2 concentrations are assigned.

Measuring a single sequence of elevation angles took about 84 s. Usually, 20 sequences were averaged to arrive at a single profile in about $28 \mathrm{~min}$.

Lidar measurements were planned to yield as much information as possible. This meant that measurements were taken:

- on clear days, to facilitate intercomparison with satellite data;

- starting early in the morning (preferably around 6:30 local time), to capture the build-up of the atmospheric boundary layer;

- at times that coincided with balloon sonde launches (see below).

\subsection{Balloon sondes}

On some of the campaign days, one or more balloon sondes with fast $\mathrm{NO}_{2}$ sensors [6] were 
launched. These reached altitudes of typically $10 \mathrm{~km}$

\section{RESULTS}

\subsection{Example profile.}

An example profile, measured with the Lidar on 15 September 2016, is shown in Figure 4. The horizontal error bars indicate the uncertainty in the measurement. The vertical bars indicate the altitude intervals over which the data points were collected. Note that the altitude axis is logarithmic, to better resolve the higher vertical resolution at lower altitudes.

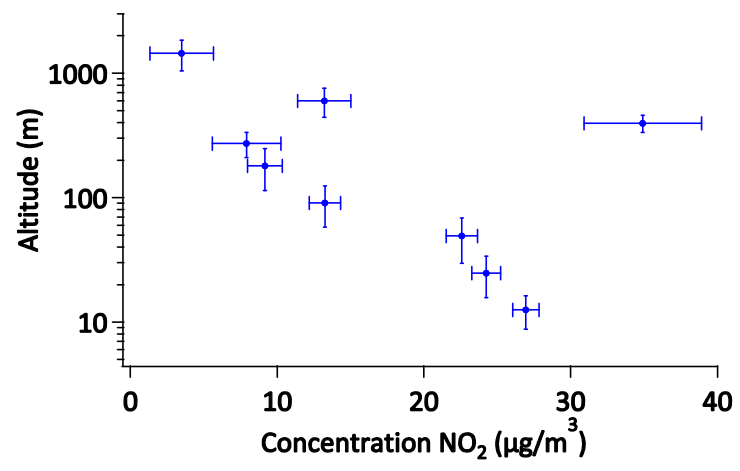

Figure 4. Example profile, measured on 15 September 2016 between 5:34 and 6:01 UTC. Local time is UTC +2 hours.

Concentrations of $\mathrm{NO}_{2}$ are highest at low altitudes and decrease with increasing altitude. Above the planetary boundary layer $\left(\begin{array}{ccc}\sim 1000 & \mathrm{~m}\end{array}\right)$ concentrations approach zero. This is as expected, as most sources are at or near the ground. The high concentration layer at $500 \mathrm{~m}$ altitude is therefore unexpected. It is, however, consistently found in other time intervals as well during several hours. An independent alternative instrument, a balloon sonde launched that day, also measures this layer.

\subsection{All profiles on one day}

The development of the concentration during 15 September 2016 is shown in Figure 5. The development of the layer around $500 \mathrm{~m}$ is clearly visible.

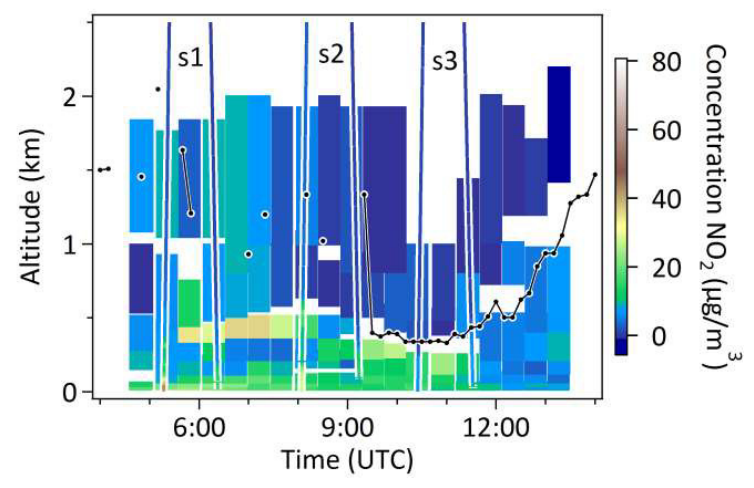

Figure 5. Example day: Thursday 15 September 2016. The traces marked 1 to 3 are balloon sonde launches on that day (see text). The black points indicate the height of the planetary boundary layer, retrieved from a ceilometer on site. Local time is UTC +2 hours.

Figure 6 shows the same day, but zoomed in on the lower altitudes during the morning. The development of the boundary layer is clearly visible, as is the influence of the weekday morning rush hour peak on the $\mathrm{NO}_{2}$ concentrations. Note that sunrise on this day was at 5:17 UTC.

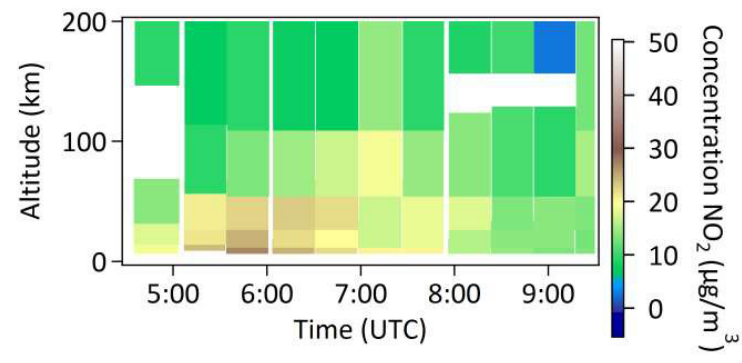

Figure 6. Example day: Thursday 15 September 2016, zoomed in.

\subsection{Comparison with balloon sonde}

In Figure 5, the traces marked s1, s2 and s3, show the lower part of the data of the three balloon sonde launches of this day. The colours of the traces indicate the concentrations measured by the sondes at the respective times and altitudes. Note that the sondes covered a considerable distance. When they measured the second part of the traces, they were located about $30 \mathrm{~km}$ from Cabauw. 


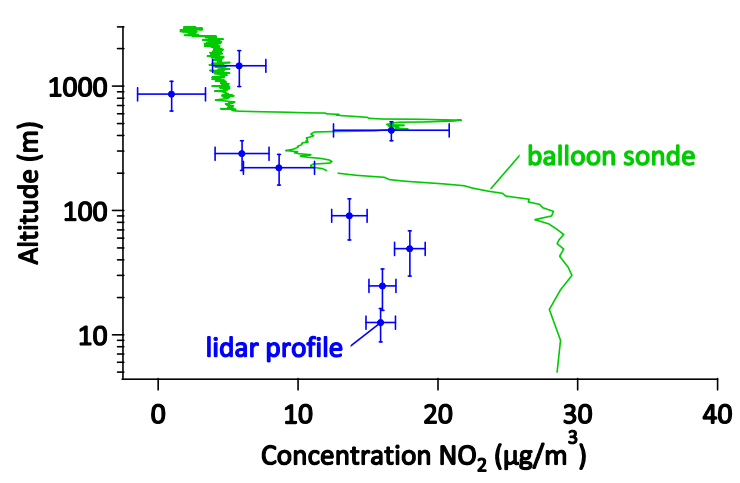

Figure 7. Lidar profile, measured on 15 September 2016 between 7:56 and 8:24 UTC, and balloon sonde, measured between 8:04 and 8:11 UTC.

Figure 7 shows the Lidar profile measured between 7:56 and 8:24 UTC, and the profile from the ascending balloon sonde, measured between 8:04 and 8:11 UTC. Lidar and sonde measure different concentrations, but the shapes of the profiles are similar. Especially striking is how well both instruments agree on the presence of the layer of elevated concentrations around $500 \mathrm{~m}$ altitude.

\subsection{All profiles from the campaign.}

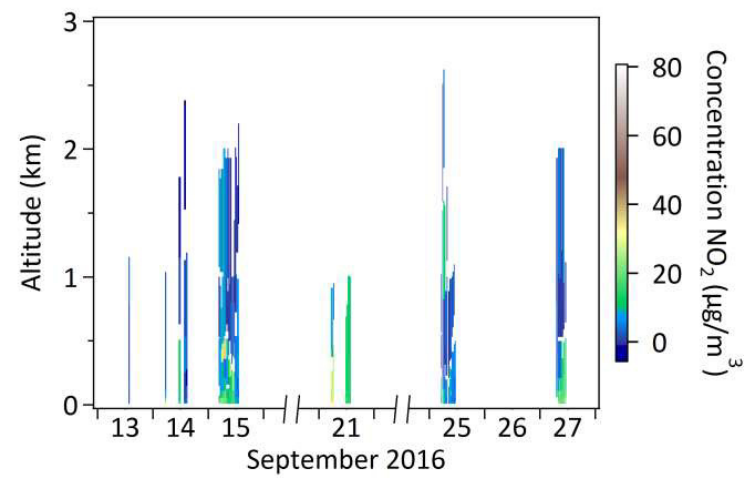

Figure 8. All profiles of the campaign.

All profiles of the campaign are shown in Figure 8. The profile of 21 September 2016 shows a similar patterns as 15 September, but with higher concentrations in the morning. On 27 September the pattern is similar as well, but the development of the rush hour peak is delayed somewhat. On 25 September, concentrations remain much lower all day long. The gaps in the day profiles on 14 and 21 September are due to instrumental problems, the days without measurements are due to unfavourable weather conditions.

\section{CONCLUSIONS}

The lidar system is well suited to mapping the atmospheric profile of $\mathrm{NO}_{2}$. The development of the atmospheric boundary layer and the dynamics of the $\mathrm{NO}_{2}$ concentration are clearly shown. At the time of writing, comparisons with only one other instrument were made, more intercomparisons will follow.

\section{ACKNOWLEDGEMENTS}

The authors wish to thank CINDI-2 organising committee for their work on this campaign. They also wish to thank Henk Klein Baltink (KNMI) for retrieving the planetary boundary layer height.

The CINDI-2 campaign was funded by the Netherlands Space (NSO) and the European Space Agency (ESA).

\section{References}

[1] Piters, A.J.M., K.F. Boersma, et al., The Cabauw Intercomparison campaign for Nitrogen Dioxide measuring Instruments (CINDI): Design, execution, and early results. Atmospheric Measurement Techniques, 2012. 5(2): p. 457-485.

[2] Volten, H., E.J. Brinksma, et al., NO2 lidar profile measurements for satellite interpretation and validation. Journal of Geophysical Research D: Atmospheres, 2009. 114(24).

[3] Berkhout, A.J.C., D.P.J. Swart, G.R. van der Hoff, and J.B. Bergwerff, Sulphur dioxide emissions of oceangoing vessels measured remotely with Lidar. RIVM, Bilthoven, Research report 609021119, 61 pp., 2012.

[4] Berkhout, A.J.C., G.R. van der Hoff, et al., Measuring ammonia emissions from manured fields. RIVM, Bilthoven, Research report 680150003, 80 pp., 2008.

[5] Berkhout, A.J.C., G.R. Van Der Hoff, and L.F.L. Gast. Lidar Measurements of Industrial Benzene Emissions. in 27th International Laser Radar Conference, ILRC 2015. 2016. EDP Sciences.

[6] Sluis, W.W., M.A.F. Allaart, A.J.M. Piters, and L.F.L. Gast, The development of $a$ nitrogen dioxide sonde. Atmospheric Measurement Techniques, 2010. 3(6): p. 1753-1762. 